\title{
Effect of Yacon (Smallanthus sonchifolius) on Colonic Transit Time in Healthy Volunteers
}

\author{
M. Geyer ${ }^{a} \quad$ I. Manrique ${ }^{b} \quad$ L. Degen ${ }^{a} \quad$ C. Beglinger ${ }^{a}$ \\ ${ }^{a}$ Department of Gastroenterology, University Hospital Basel, Basel, Switzerland; b International Potato Center, \\ Lima, Peru
}

\section{Key Words}

Yacon - Fructooligosaccharides - Gastrointestinal motility •

Diabetics $\cdot$ Constipation needed in constipated patients to confirm these preliminary data. Due to the low caloric content of yacon, the root could be a useful treatment in constipated diabetics or obese patients.

Copyright $\odot 2008$ S. Karger AG, Basel

\begin{abstract}
Background: Yacon is a root crop which contains high amounts of fructooligosaccharides (FOS). The aim of this study was to investigate the effects of yacon syrup on colon transit time in healthy volunteers. Methods: In a placebocontrolled, double-blind study yacon was administered to 16 healthy individuals ( 8 males, 8 females) in a dose of $20 \mathrm{~g}$ daily (equal to $6.4 \mathrm{~g} \mathrm{FOS}$ ) in a 2-week crossover design. Each period was interrupted by a 2-week wash-out phase. Transit time was assessed by a radio-opaque marker technique. $\boldsymbol{R e}$ sults: Transit time (mean \pm SEM) through the gastrointestinal tract was significantly decreased from $59.7 \pm 4.3$ to 38.4 $\pm 4.2 \mathrm{~h}(\mathrm{p}<0.001)$. Yacon was well tolerated with an excellent side effect profile. Bloating is not an uncommon side effect observed with FOS, but bloating-related disturbances were not significantly more often reported with yacon compared to placebo. Stool frequency increased from $1.1 \pm 0.1$ to $1.3 \pm 0.2$ times per day and the consistency showed a tendency for softer stools as assessed by a numerical depicted stool protocol. Neither parameter did, however, reach statistical significance. Conclusion: Yacon markedly accelerates colonic transit in healthy individuals. Further studies are
\end{abstract}

\section{Introduction}

Yacon is a scientifically little known root crop taxonomically classified under the Asteraceaea family that is native to the Andean region $[1,2]$. It is cultivated up to a height of 3,200 $\mathrm{m}$ above sea level and consumed since preInca times. Interest in this crop has increased as it is a plant source with the largest content of fructooligosaccharides (FOS). Yacon was recently introduced to several different regions with varying climates: Brazil, Czech Republic, China, Korea, Japan, New Zealand, Russia, Taiwan and the United States [1,2]. Yacon is well tolerated with no known toxic effects [3].

FOS are accepted in most countries as food ingredients that can be used without restrictions in food formulations [4]. FOS are low in calories and consumption is known to promote health of the intestinal tract. FOS resist the hydrolysis of enzymes in the human digestive system and are therefore able to reach the colon without being digested or metabolized. In the colon, FOS are com-

\section{KARGER}

Fax +4161306 1234 E-Mail karger@karger.ch www.karger.com
(C) 2008 S. Karger AG, Base

0012-2823/08/0781-0030\$24.50/0

Accessible online at:

www.karger.com/dig
Martin Geyer

Rosengartenstrasse 2

$\mathrm{CH}-5430$ Wettingen (Switzerland)

Tel. +41 5642628 33, Fax +41564265333

E-Mail geyer@gastroenterologie-wettingen.ch 
pletely fermented [5] to short fatty acids (e.g. butyrate, acetate propionate) [6]. These effects can prevent and control constipation [7] and make the FOS an interesting substance.

Yacon syrup is a novel product, which contains up to $50 \%$ FOS, made by concentrating the juice of the tuberous storage roots of yacon. Production technology depends on an evaporator, which is commonly used for the production of maple syrup. The physical and sensorial characteristics of yacon syrup are similar to those of honey, maple syrup or sugar cane syrup with the advantage of low caloric intake (even to be recommended for diabetics) $[8,9]$. However, clinical studies are required to substantiate the benefits of yacon consumption. To our knowledge, there have been no human placebo-controlled studies that demonstrate the laxative effect of yacon. The aim of this study was therefore to investigate in healthy volunteers the effects of yacon syrup on gastrointestinal motility quantified by colon transit time measurement. We hypothesized that yacon syrup would accelerate colon transit time in comparison to placebo.

\section{Methods}

The study was conducted as a randomized, placebo-controlled study at the University Hospital of Basel. The local ethical committee approved the protocol and all subjects gave written informed consent. 16 healthy volunteers ( 8 females, 8 males) aged $18-57$ years of age (mean age of $29.3 \pm 4.9$ years) were recruited for the study. Exclusion criteria were chronic constipation (less than 3 bowel movements per week and ROME criteria), diarrhea (more than 3 bowel movements per day), IBS symptoms according to ROME II criteria, relevant concomitant cardiovascular, renal, hematological, neurological, psychiatric, hepatological, intestinal disease including abdominal operation (exception appendectomy) and pregnancy. Any kind of medication that could potentially influence bowel activity was prohibited (intake of laxatives and bran). Body size and weight had to be within normal ranges. For all females, a pregnancy test was obligatory. Physical activity was only allowed in moderate limits within individual habits.

\section{Study Design}

The trial was conducted as a randomized, placebo-controlled, two-period, crossover study. Each period lasted for 2 weeks. In one period, subjects received $20 \mathrm{~g}$ placebo syrup ( $20 \mathrm{~g}$ molasses) per day, in the second period $20 \mathrm{~g}$ yacon syrup per day. The chemical composition of the yacon syrup we used is shown in table 1. A pharmacist, who was not involved in the trial, prepared the bottles with the respective syrups. The two preparations were morphologically identical and delivered in brown containers together with a dosing cup of $20 \mathrm{ml}$, thereby making it possible to dose them in a double-blind fashion. The color, smell and taste of both syrups were similar: brown and sweet.

Effect of Yacon on Colonic Transit Time
Table 1. Chemical composition of tested yacon syrup sample

$\begin{array}{lc}\text { Total carbohydrate, \% } & 67 \\ \quad \text { FOS, \% } & 32 \\ \quad \text { Simple sugars (glucose, fructose, sucrose), \% } & 35 \\ \text { Protein, \% } & 2.3 \\ \text { Fat, \% } & 0.4 \\ \text { Ash, \% } & 3.2 \\ \text { Water, \% } & 29.5 \\ \text { Potassium, mg/kg } & 9,838.5 \\ \text { Sodium, mg/kg } & 830.38\end{array}$

Yacon syrup was prepared according to technical standards published [7].

The sequence of treatment was randomized. A washout period of 2 weeks was applied between two study periods. The primary endpoint of the study was the colonic transit time (CTT) using the radio-opaque marker technique. In brief, 10 radio-opaque markers were ingested on 6 consecutive days (from day 9 to day 14 of each period); $24 \mathrm{~h}$ after ingestion of the last set of markers, a plain abdominal X-ray picture was taken in the supine position. CTT was calculated as previously described [10]. As secondary endpoints daily stool frequency, and stool consistency and side effects were assessed using questionnaires. For assessment of stool consistency, a standardized stool protocol was used as depicted in figure 1 [11].

\section{Calculations and Statistics}

Data are presented as mean \pm SD unless indicated otherwise. Transit times (segmental and total colonic transit) were compared between the treatment groups by analysis of variance using sex as a covariate. The level of significance was $p=0.05$. Tests were performed using SPSS for Windows v15.0.

\section{Results}

\section{Colonic Transit Time}

The results on CTT are depicted in table 2 and figure 2. Yacon treatment induced a marked acceleration of CTT, $\mathrm{p}<0.001$. The effect was mainly due to an acceleration of transit in the right colon. There was no significant effect of gender on transit time.

\section{Stool Parameters}

Stool frequency with placebo averaged 1.1 (SD 4.2) bowel movements per day (range 0.6-2.4 bowel movements per day), whereas stool consistency according to visual scoring (fig. 1) averaged 2.7 (SD 0.7, range 1.5-4.0). Bloating measured as days with bloating was less than 1 day out of 14 days with placebo treatment (mean 0.87 , SD 


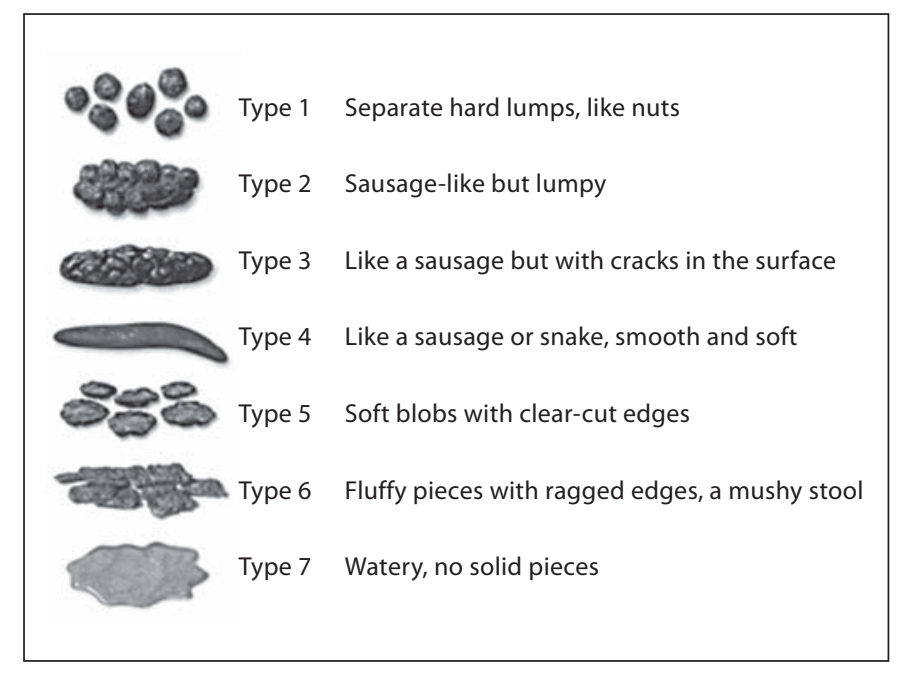

Fig. 1. Stool consistency as depicted by the Bristol Stool Form Scale [11].

Table 2. Effect of yacon on segmental and total transit time (h) in 16 healthy volunteers

\begin{tabular}{lccl}
\hline & Placebo & Yacon & p value \\
\hline Right colon & $22.8 \pm 4.0$ & $10.5 \pm 2.4$ & 0.013 \\
Left colon & $24.0 \pm 2.9$ & $20.3 \pm 3.1$ & NS \\
Sigmoid rectum & $14.5 \pm 4.1$ & $9.6 \pm 2.3$ & NS \\
Total CTT & $59.7 \pm 4.3$ & $38.4 \pm 4.2$ & 0.001 \\
\hline
\end{tabular}

Data are means \pm SEM.

1.1 ; range $0-3)$. With yacon treatment, the mean stool frequency was slightly, albeit nonsignificantly increased from 1.1 to 1.3 (range $0.6-2.4 ; \mathrm{p}=0.17$ ), as was the stool consistency, which marginally increased from 2.7 to a value of 2.8 (range $1.7-4.1 ; \mathrm{p}=0.48$ ). The mean number of days with bloating was not significantly different between the two groups (placebo 0.87, SD 1.1; yacon 0.6, SD 1.0). The risk profile was excellent and no treatment-associated side effects were reported during the study.

\section{Discussion}

The results of the present study can be summarized as follows: in this placebo-controlled crossover study, yacon syrup in a dose of $20 \mathrm{~g}$ daily (equal to $6.4 \mathrm{~g}$ FOS) induced a marked acceleration of CTT in healthy volunteers as as-

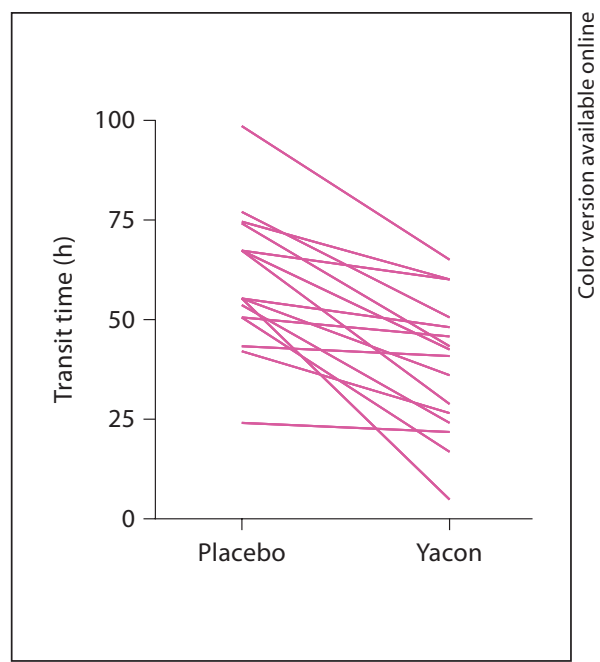

Fig. 2. Individual transit times during placebo versus yacon treatment. CTT was markedly accelerated in all 16 subjects.

sessed by a radio-opaque marker technique. All subjects demonstrated a marked decrease in CTT. In addition, we observed a trend for slightly increased stool frequency and for softer stool consistency, although both parameters did no reach statistical significance.

Oligofructose is a dietary fiber with a potential for clinical application. FOS resists digestion by gastric acid and pancreatic enzymes in vivo. A key property of these fibers lies in the indigestibility of oligosaccharides, which gives rise to fermentation in the large intestine followed by an increase in Bifidobacteri and Lactobacilli. The process results in an increased short-chain fatty acid production (prebiotic effect). In 21 human subjects taking $6 \mathrm{~g}$ of FOS, the number of Bifidobacteri clearly increased within a week [12]. This property can induce several effects. First, normalization of stool frequency with an improvement of constipation $[6,13]$ has been reported, suggesting that FOS is acting as a laxative. Second, mineral absorption is increased, which leads to a rise in bone density [14-16]. Third, an immunomodulatory effect and a potential for cancer prevention have been postulated [5].

Through the stimulation of bacterial growth and production of short-chain fatty acids as a major product of bacterial fermentation, bowel habits are affected and FOS is acting as a laxative. A Taiwanese group conducted a controlled pilot study in 5 constipated subjects for twice 30 days [6]. In the 30-day period in which $10 \mathrm{~g}$ FOS was supplemented, defecation frequency, daily stool weight, and weight per individual stool were significantly augmented. In addition, calcium and phosphate levels in 
plasma were increased. The authors concluded that supplementation of FOS was able to alleviate constipation in elderly men [6]. In the present study, we can document that FOS in the form of yacon syrup accelerates colonic transit; the findings form the basis for a controlled clinical evaluation of yacon in patients with constipation.

Yacon was well tolerated in the present study in healthy subjects and no severe side effects were observed. FOS at high doses can increase flatulence and osmotic pressure and therefore cause intestinal discomfort [3]. There was, however, no statistical difference in bloating scores between yacon treatment and control (molasses) in our study.

Further studies in constipated patients are needed to confirm the data of this preliminary study in healthy individuals. Dose-response relationships should be per- formed in constipated subjects and a probably higher dose than $20 \mathrm{~g}$ yacon daily needs to be tested for a more potent action as a laxative. Because yacon syrup has a low caloric content, constipated obese persons or diabetics would be an ideal target group. Beside the laxative effect of yacon, other effects such as the probiotic, calcium absorptive, cholesterol- and triglyceride-reducing effects as shown in animal models [13-16] should be investigated in human studies.

\section{Acknowledgements}

We thank Prof. Jürgen Drewe for statistical support and Prof. Jürg Schifferli, University Hospital Basel, and the Altana fund of Internal Medicine for supporting this study.

\section{References}

$1 \mathrm{http}: / /$ www.greenharvest.com.

2 Seminario J, Valderrama M, Manrique I: El yacón: fundamentos para el aprovechamiento de un recurso promisorio. Centro Internacional de la Papa (CIP), Universidad Nacional de Cajamarca, Agencia Suiza para el Desarrollo y la Cooperación (COSUDE), Lima, 2003, p 60.

3 Genta SB, Cabera WM, Grau A, Sánchez SS: Subchronic 4-month oral toxicity study of dried Smallanthus sonchifolius (yacon) roots as a diet supplement in rats. Food Chem Toxicol 2005;43:1657-1665.

4 Coussement PA: Inulin and oligofructose: safe intakes and legal status. J Nutr 1999; 129(suppl 7):1412S-1417S.

$\checkmark 5$ Silva RF: Use of inulin as a natural texture modifier. Cereal Food World 1996;41:792794.

6 Hirayama M: Novel physiological functions of oligosaccharides. Pure Appl Chem 2002; 74:1271-1279.

$\checkmark 7$ Chen HL, Lu YH, Lin J, Ko LY: Effects of fructooligosaccharide on bowel function and indicators of nutritional status in constipated elderly men. Nutr Res 2000;20:17251733.
8 Manrique I, Párraga A, Hermann M: Yacon syrup: principles and processing; in Conservación y uso de la biodiversidad de raíces y tubérculos andinos: una década de investigación para el desarrollo (1993-2003). No. 8B. International Potato Center, Universidad Nacional Daniel Alcides Carrión, Erbacher Foundation, Swiss Agency for Development and Cooperation, Lima, 2005, p 31.

-9 Luo J, Van Yperselle M, Rizkalla S, Rossi F, Bornet F, Slama G: Chronic consumption of short-chain fructooligosaccharides does not affect basal hepatic glucose productin or insulin resistance in type 2 diabetics. J Nutr 2000;130:1572-1577.

10 Meier R, Beglinger C, Dederding JP, MeyerWyss B, Fumagalli M, Rowedder A, Turberg Y, Brignoli R: Influence of age, gender, hormonal status and smoking habits on colonic transit time. Neurogastroenterol Motil 1995; 7:235-238.
O’Donnell LJ, Virjee J, Heaton KW: Detection of pseudodiarrhoea by simple clinical assessment of intestinal transit rate. BMJ 1990;300:439-440.

12 Mitsuoka T, Hidaka H, Eida T: Effect of fructo-oligosaccharides on intestinal microflora. Nahrung 1987;31:427-436.

13 Cummings JH, Macfarlane GT, Englyst HN: Prebiotic digestion and fermentation. Am J Clin Nutr 2000;73(suppl):415S-420S.

14 Scholz-Ahrens KE, Acil Y, Schrezenmeir J: Effect of oligofructose or dietary calcium on repeated calcium and phosphorus balances, bone mineralization and trabecular structure in ovariectomized rats. Br J Nutr 2002; 88:365-377.

15 Scholz-Ahrens KE, Schrezenmeir J: Inulin, oligofructose and mineral metabolism experimental data and mechanism. Br J Nutr 2002;87(suppl 2):S179-S186.

16 Kruger MC, Brown KE, Collett G, Layton L, Schollum LM: The effect of fructooligosaccharides with various degrees of polymerisation on calcium bioavailability in the growing rat. Exp Biol Med 2003;228:683-688. 